EESTI NSV TEADUSTE AKADEEMIA TOIMETISED. XVI KÖIDE

KEEMIA * GEOLOOGIA. 1967, Nr. 3

ИЗВЕСТИЯ АКАДЕМИИ НАУК ЭСТОНСКОЙ ССР. ТОМ ХVI

ХИМИЯ * ГЕОЛОГИЯ. 1967, № 3

Ю. ЭИЗЕН, С. РАНГ, В. КАСК, О. ЭИЗЕН

\title{
ИНФРАКРАСНЫЕ СПЕКТРЫ НЕКОТОРЫХ УГЛЕВОДОРОДОВ ЦИКЛОГЕКСЕНОВОГО РЯДА
}

\section{-. Сообщение второе}

В настоящей. статье, являющейся продолжением работы [1], обсуждается возможность идентификации соединений циклогексенового ряда в инфракрасной спектральной области. Если в [ $\left.{ }^{1}\right]$ рассматривались спектральные закономерности 1- и 3-моноалкилцнклогексенов $\mathrm{C}_{7}-\mathrm{C}_{10}$, то здесь представлен материал по различным циклогексенам $\mathrm{C}_{\mathrm{H}}-\mathrm{C}_{16}$.

Соединения циклогексенового ряда были синтезированы согласно методике, приведенной в [1], и очищены методом препаративной газовой хроматографии. Степень чистоты полученных при этом веществ характеризуется в табл. 1.

\section{Таблица 1}

Чистота циклогексеновых углеводородов, использованных для спектральных исследований

\begin{tabular}{l|r|r}
\hline \multirow{2}{*}{ Углеводорсд } & Изомер-1 & Изомер-3 \\
\cline { 2 - 3 } & \multicolumn{2}{|c}{$\%$} \\
\hline & & \\
Пентилциклогексен-1 & 89,0 & 98,8 \\
Гексилциклогексен-1 & 98,6 & 100,0 \\
Гептилциклогексен-1 & 94,6 & 100,0 \\
Октилциклогексен-1 & 87,4 & 94,5 \\
Нонилциклогексен-1 & 94,1 & 98,0 \\
Фенилциклогексен-1 & 100,0 & 100,0 \\
Бензилциклогексен-1 & 98,3 & 100,0 \\
Аллилциклогекен-1 & 98,0 & 100,0 \\
Циклогексилциклогексен-1 & 100,0 & 98,5
\end{tabular}

Спектры снимались в области $400-3100 \mathrm{~cm}^{-1}$ с призмами из $\mathrm{KBr}$, $\mathrm{NaCl}$ и $\mathrm{LiF}$, без растворителя, при толщине слоя 0,03 и 0,002 мм на спектрографе UR-10. Волновые числа абсорбционных максимумов уточнялись по спектру полистирола. Результаты опытов приведены в табл. 2 н на рис. 1 и 2.

Как уже отмечалось в [1], в области волновых чисел $3100-2800 \mathrm{~cm}^{-1}$ для определения различия между спектрами 1- и 3-алкилзамещенных

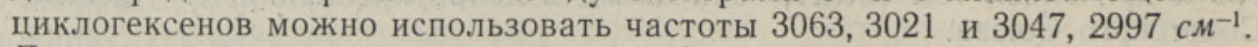
Две первые частоты характерны для 3-алкилциклогексенов, вторые для 1 -алкилциклогексенов. Согласно Х. Шиманскому $\left[{ }^{2}\right]$, волновые числа валентных колебаний группы $=\mathrm{CH}$ отвечают области $3040-3010 \mathrm{~cm}^{-1}$ 
Абсорбционные максимумы циклогексенов

Углеводород

1-Пентилциклогексен-1

1-Гексилциклогексен-1

1-Гептнлциклогексен-1

ๆ-Октилциклогексен-1

1-Нонилциклогексен-1

1-Аллилциклогексен-1

1-Изоамилциклогексен-1

3-Пентилцнклогексен-1

3-Гексилциклогексен-1

3-Гептилциклогексен-1

3-Октилциклогексен-1

3-Нонилциклогексен-1

3-Бензилциклогексен-1

3-Фенилциклогексен-1

3-Аллнлциклогексен-1

3-Цнклогекснлциклогексен-1
Волновые чнсла, отвечающие абсорбционным максимумам, cu-1

$\begin{array}{llllllllllllllllll}541 & 724 & 743 & 754 & 758 & 800 & 828 & 843 & 858 & 894 & 912 & 918 & 934 & 968 & 1022 & 1045 & 1070 & 1103\end{array}$

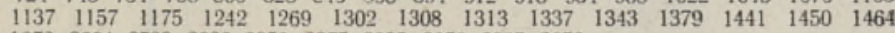

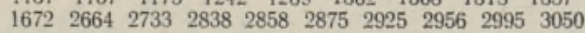

$\begin{array}{llllllllllllllllll}538 & 725 & 746 & 762 & 800 & 831 & 848 & 858 & 884 & 890 & 918 & 936 & 965 & 988 & 996 & 1021 & 1048 & 1072\end{array}$ $\begin{array}{llllllllllllll}1105 & 1137 & 1157 & 1181 & 1241 & 1270 & 1311 & 1344 & 1381 & 1443 & 1452 & 1465 & 1673 & 2669\end{array}$

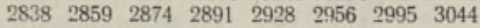

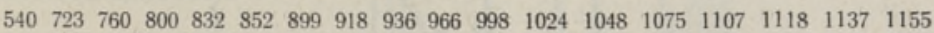
$\begin{array}{llllllllllllllllll}1180 & 1235 & 1243 & 1295 & 1310 & 1341 & 1345 & 1380 & 1443 & 1450 & 1467 & 1674 & 2664 & 2837 & 2858\end{array}$ $\begin{array}{lllll}2874 & 2923 & 2954 & 2997 & 3046\end{array}$

$\begin{array}{llllllllllllllllll}538 & 609 & 644 & 721 & 750 & 754 & 766 & 771 & 797 & 829 & 860 & 917 & 1051 & 1077 & 1106 & 1137 & 1158 & 1179\end{array}$ $\begin{array}{lllllllllllllll}1243 & 1271 & 1311 & 1344 & 1380 & 1442 & 1450 & 1458 & 1466 & 1470 & 1672 & 2667 & 2838 & 2856 & 2873\end{array}$ 2927295730003047

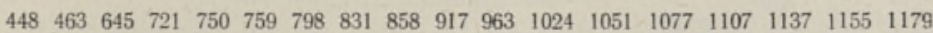

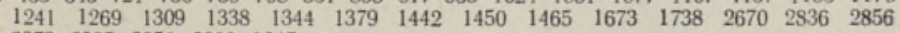
$\begin{array}{lllll}2873 & 2925 & 2956 & 2998 \quad 3047\end{array}$

$\begin{array}{lllllllllllllllllll}438 & 448 & 512 & 550 & 583 & 677 & 691 & 706 & 760 & 799 & 818 & 829 & 857 & 882 & 913 & 947 & 972 & 994 & 1045\end{array}$

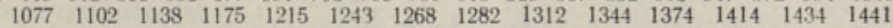
$\begin{array}{llllllllllllll}1451 & 1460 & 1642 & 1674 & 1737 & 1751 & 1828 & 2659 & 2678 & 2837 & 2560 & 2882 & 2894 & 2929\end{array}$ 298030063082

$\begin{array}{lllllllllllllllllll}461 & 533 & 551 & 610 & 675 & 697 & 721 & 746 & 761 & \$ 01 & 826 & 840 & 863 & 905 & 920 & 940 & 963 & 1048 & 1070\end{array}$ $\begin{array}{llllllllllllll}1110 & 1121 & 1141 & 1160 & 1172 & 1210 & 1246 & 1273 & 1314 & 1343 & 134 ? & 1362 & 1391 & 1445\end{array}$ $\begin{array}{llllllllllllllllllll}1456 & 1475 & 1676 & 1698 & 1720 & 1736 & 2664 & 2721 & 2841 & 2862 & 2874 & 2939 & 2959 & 3000 & 3049\end{array}$

$\begin{array}{llllllllllllllllll}460 & 538 & 595 & 675 & 697 & 720 & 764 & 797 & 840 & 859 & 885 & 905 & 910 & 923 & 958 & 1059 & 1120 & 1142\end{array}$

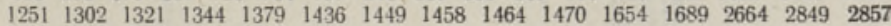
$28742928 \quad 29593021 \quad 3063$

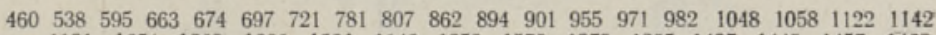
$\begin{array}{lllllllllllllll}1181 & 1254 & 1268 & 1306 & 132 ! & 1342 & 1352 & 1370 & 1378 & 1395 & 1437 & 1448 & 1457 & 1468\end{array}$ $\begin{array}{lllllllllllllll}1659 & 1691 & 1735 & 2661 & 2731 & 2837 & 2854 & 2864 & 2925 & 2956 & 3021 & 3063\end{array}$

$\begin{array}{llllllllllllllllll}541 & 595 & 665 & 676 & 695 & 721 & 768 & 798 & 862 & 876 & 907 & 928 & 957 & 967 & 1049 & 1059 & 1086 & 1112\end{array}$

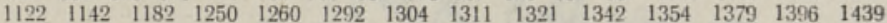
$\begin{array}{lllllllllllll}1451 & 1457 & 1468 & 1660 & 1693 & 2662 & 2732 & 2856 & 2925 & 2956 & 3023 & 3063\end{array}$

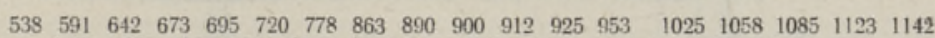
$\begin{array}{lllllllllllllllll}1179 & 1258 & 1320 & 1344 & 1372 & 1380 & 1439 & 1450 & 1459 & 1468 & 1658 & 1745 & 2661 & 2730 & 2839\end{array}$

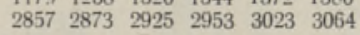

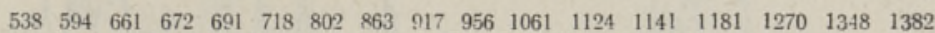
$\begin{array}{lllllllllllllll}1438 & 1454 & 1459 & 1469 & 1655 & 2655 & 2857 & 2927 & 2957 & 3021 & 3061\end{array}$

$\begin{array}{lllllllllllllllllll}458 & 503 & 524 & 589 & 618 & 664 & 670 & 696 & 720 & 743 & 763 & 793 & 810 & 850 & 863 & 914 & 930 & 941 & 952\end{array}$ $\begin{array}{lllllllllllllllll}1005 & 1029 & 1042 & 1062 & 1080 & 1089 & 1133 & 1181 & 1213 & 1228 & 1250 & 1273 & 1322 & 1350 & 1399\end{array}$ $\begin{array}{lllllllllllllll}1438 & 1451 & 1458 & 1500 & 1589 & 1609 & 1657 & 1692 & 1727 & 1804 & 1877 & 1949 & 2048 & 2059 & 2841\end{array}$ $\begin{array}{lllllll}2850 & 2927 & 3027 & 3065 & 3086 & 3111\end{array}$

$\begin{array}{lllllllllllllllllll}457 & 507 & 526 & 596 & 675 & 703 & 725 & 741 & 757 & 791 & 845 & 880 & 894 & 910 & 923 & 933 & 983 & 993 & 1003\end{array}$ $\begin{array}{lllllllllllllll}1029 & 1040 & 1062 & 1074 & 1112 & 1134 & 1146 & 1154 & 1179 & 1189 & 1220 & 1248 & 1263 & 1273\end{array}$ $\begin{array}{lllllllllllllllll}1300 & 1323 & 1337 & 1434 & 1454 & 1495 & 1584 & 1602 & 1650 & 1706 & 1746 & 1819 & 1879 & 1941 & 2663\end{array}$

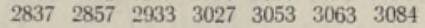

$\begin{array}{lllllllllllllllllll}454 & 458 & 532 & 549 & 619 & 635 & 666 & 687 & 699 & 724 & 787 & 798 & 853 & 863 & 913 & 940 & 964 & 994 & 1032\end{array}$ $\begin{array}{lllllllllllllll}1049 & 1060 & 1088 & 1111 & 1124 & 1144 & 1173 & 1214 & 1221 & 1230 & 1248 & 1271 & 1297 & 1318\end{array}$ $\begin{array}{llllllllllllllllll}1320 & 1347 & 1399 & 1418 & 1442 & 1451 & 1644 & 1689 & 1736 & 1831 & 2658 & 2838 & 2859 & 2926 & 2982\end{array}$ 302130693080

$\begin{array}{lllllllllllllllllll}458 & 486 & 531 & 541 & 561 & 602 & 676 & 700 & 721.738 & 752 & 772 & 793 & 811 & 847 & 864 & 872 & 890 & 901\end{array}$

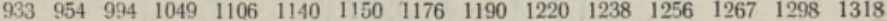

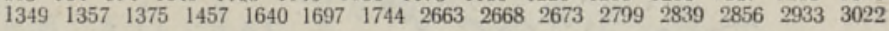

как в случае олефинов типа $\mathrm{CRR}=\mathrm{CHR}$, цис-CHR $=\mathrm{CHR}$, так и транс$\mathrm{CHR}=\mathrm{CHR}$. Этой области принадлежит валентное колебание $3021 \mathrm{~cm}^{-1}$ 3 -алкилциклогексенов. По всей вероятности, сюда же относится и частота $2997 \mathrm{CM}^{-1}$, характерная для 1-алкилциклогексенов. По сравнению c абсорбцией при частоте 3021 c $^{-1}$ абсорбция при частотах 3063,3047 и 2997 слаба. И. Шабтай и др. [3] отмечают отсутствие максимума $3020 \mathrm{~cm}^{-1}$ у 3-этил- и 3-изопропилциклогексенов. Согласно нашим данным ['], этот максимум наблюдается при частотах 3018-3020 $\mathrm{cm}^{-1}$.

Ярко выраженные максимумы 2939, 2856 отвечают асимметричным я симметричным валентным колебаниям группы $-\mathrm{CH}_{2}-$, в то время 

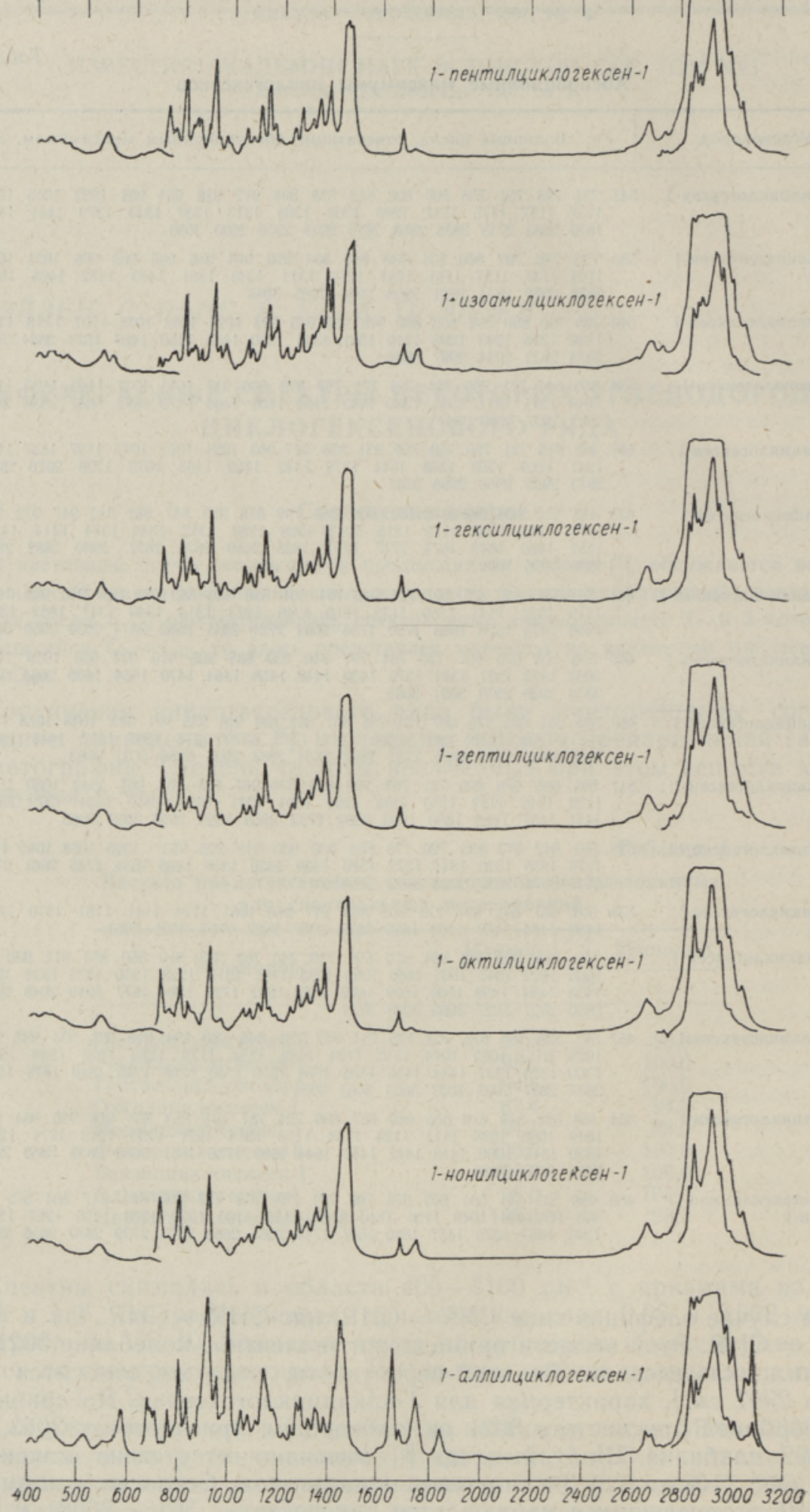

Рис. 1. Инфракрасные спектры 1-замещенных циклогексенов-1. 
$\begin{array}{llllllllllllllll}400 & 500 & 600 & 800 & 1000 & 1200 & 1400 & 1600 & 1800 & 2000 & 2200 & 2400 & 2600 & 2800 & 3000 & 3200\end{array}$
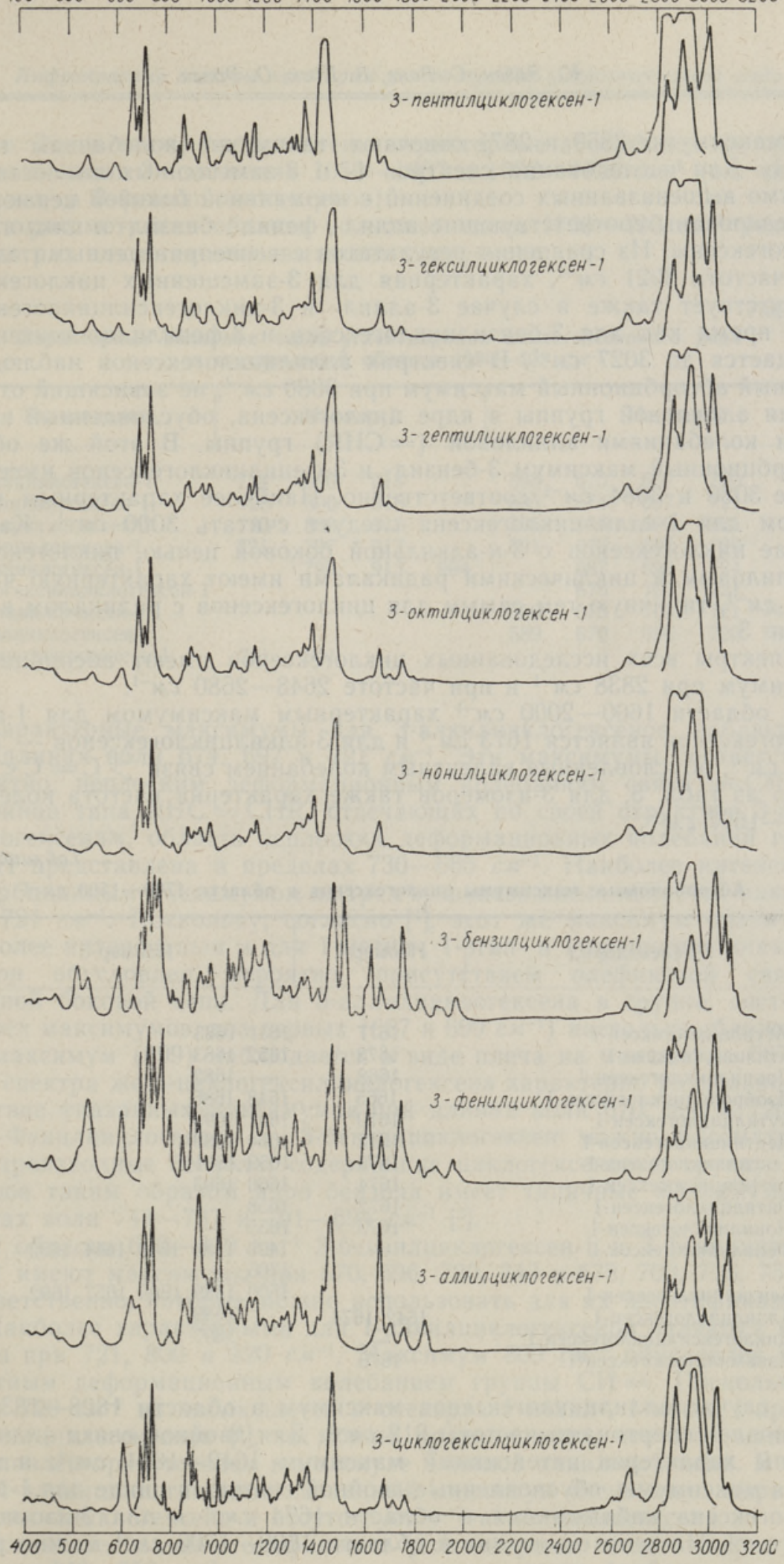

Рис. 2. Инфракрасные спектры 3-замещенных циклогексенов-1. 
как максимумы 2859 и 2871 отвечают таким же колебаниям группы - $\mathrm{CH}_{3}$. Для исследования спектров 1- и 3-замещенных циклогексенов, помимо вышеназванных соединений с нормальной боковой цепью, были синтезированы соответствующие аллил-, фенил-, бензил- и циклогексилциклогексены. Из сравнения результатов с вышеприведенными следует, что частота $3021 \mathrm{CM}^{-1}$, характерная для 3-замещенных циклогексенов, присутствует также в случае 3-аллил- и 3-циклогексилциклогексенов, в то время как для 3-бензилциклогексена и 3-фенилциклогексена она смещается до $3027 \mathrm{~cm}^{-1}$. В спектрах аллилциклогексенов наблюдается сильный абсорбционный максимум при $3080 \mathrm{~cm}^{-1}$, не зависящий от положения аллиловой группы в ядре циклогексена, обусловленный валентными колебаниями аллиловой $(=\mathrm{CHR})$ группы. В этой же области абсорбционный максимум 3-бензил- и 3-фенилцнклогексенов имеет значение 3086 и 3084 cm $^{-1}$ соответственно. Наиболее характерным максимумом для 1-аллилциклогексена следует считать 3000 c. ${ }^{-1}$. Как и в случае циклогексенов с 3-н-алкильной боковой цепью, циклогексены с 3-аллиловым и циклическими радикалами имеют характерную частоту $3063 \mathrm{~cm}^{-1}$, типичную тем самым для циклогексенов с радикалом в положении 3.

Спектры всех исследованных циклогексенов имеют абсорбционный максимум при $2838 \mathrm{~cm}^{-1}$ и при частоте $2648-2680 \mathrm{CM}^{-1}$.

В области $1600-2000 \mathrm{~cm}^{-1}$ характерным максимумом для 1-алкилциклогексенов является $1673 \mathrm{~cm}^{-1}$ и для 3 -алкилциклогексенов - 1651$1660 \mathrm{~cm}^{-1}$, обусловленные валентным колебанием связи $>\mathrm{C}=\mathrm{C}<$. Как видно из табол. 3, для 3-изомеров также характерна частота колебания $1683-1697 \mathrm{CM}^{-1}$.

Таблица 3

Абсорбционные максимумы циклогексенов в области $1700-1500 \mathrm{~cm}^{-1}$

\begin{tabular}{l|l|l}
\hline Углеводород & Изомер-1 & Изомер-3 \\
\hline
\end{tabular}

Метилциклогексен-1 Этилциклогексен-1 Прспилциклогексен-1 Изопропнлциклогексен-1 Бутилциклогексен-1 Пентилциклогексен-1 Гексилциклогексен-1 Гептилциклогексен-1 Октилциклогексен-1 Нонилциклогексен-1 Фенилциклогексен-1

Бензилциклогексен-1 Аллилциклогексен-1 Циклогексилщиклогексен-1 Изоамилциклогексен-1

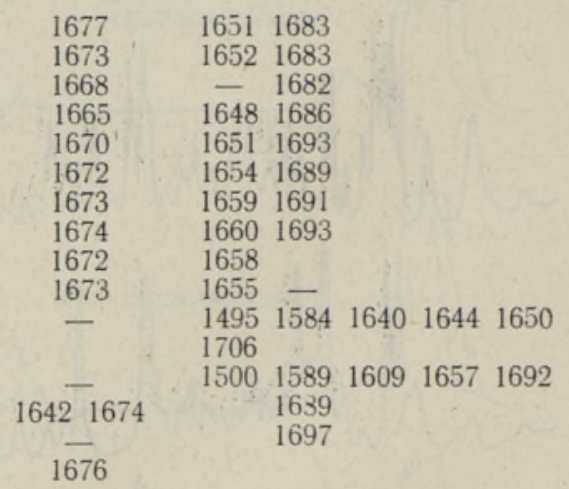

В случае аллилциклогексенов максимум в области $1828-1831 \mathrm{~cm}^{-1}$ обусловлен обертонами частоты $912 \mathrm{~cm}^{-1}$. Для двойной связи аллиловой группы характерен интенсивный максимум $1642-1644 \quad$ c. $^{-1}$; в то же время максимумы, обусловленные двойной связью, в цикле для 1-аллилциклогексена наблюдаются в области $1674 \mathrm{~cm}^{-1}$ и для 3-изомера $1689 \mathrm{~cm}^{-1}$. На этом основании в области $1600-1700 \mathrm{~cm}^{-1}$ можно различать типы двойной связи.

Труднее интерпретировать максимумы ароматических циклогексенов. Максимумы $1500,1584-1589,1602-1609$ обусловлены ароматическим 
ядром. Здесь также представлены характерные абсорбционные области для замешения 3-положения $1650-1657$ и $1692-1706$ см $^{-1}$ (см. спектры 3-бензил- и 3-фенилциклогексенов).

Из рассмотрения области волновых чисел 1000-400 c.⿲丿丨 в спектрах циклогексенов вытекает следующее.

Характерные волновые числа углеводородов циклогексенового ряда в спектральной области $1000-400 \mathrm{~cm}^{-1}$

\begin{tabular}{|c|c|c|c|c|c|c|c|c|c|}
\hline Углеводород & & Изол & ep-1 & & & & Изом & -3 & \\
\hline $\begin{array}{l}\text { Пентилциклогексен-1 } \\
\text { Гексилциклогексен-1 } \\
\text { Гептилциклогексен-1 } \\
\text { Октилциклогексен-1 } \\
\text { Аллилциклогексен-1 } \\
\text { Циклогексилциклогексен-1 } \\
\text { Фенилциклогексен-1 } \\
\text { Бензилциклогексен-1 }\end{array}$ & $\begin{array}{l}724 \\
725 \\
723 \\
721\end{array}$ & $\begin{array}{l}800 \\
800 \\
800 \\
797 \\
799\end{array}$ & $\begin{array}{l}918 \\
918 \\
918 \\
917 \\
913\end{array}$ & 994 & $\begin{array}{l}595 \\
595 \\
595 \\
591\end{array}$ & $\begin{array}{l}675 \\
674 \\
676 \\
673 \\
687 \\
676 \\
675 \\
670\end{array}$ & $\begin{array}{l}697 \\
697 \\
696 \\
695 \\
699 \\
700 \\
703 \\
696\end{array}$ & $\begin{array}{l}720 \\
721 \\
721 \\
720 \\
724 \\
721 \\
721 \\
720\end{array}$ & $\begin{array}{ll}741 & \\
743 & 757\end{array}$ \\
\hline
\end{tabular}

Изоамилинилогексен-1

Характерные максимумы для 3-алкилциклогексенов наблюдаются при длинах волн 674, 697 и $721 \mathrm{~cm}^{-1}$. Эти максимумы соответствуют, вероятно, неплоским деформационным колебаниям связи $=\mathrm{CH}$. Для олефинов типа RHC $=\mathrm{CHR}$, отвечающих по своей структуре 3-алкилциклогексенам, область неплоских деформационных колебаний группы $=\mathrm{CH}$ представлена в пределах $730-665 \mathrm{~cm}^{-1}$. Наиболее интенсивным абсорбционным максимумом из трех вышеназванных является максимум при $721 \mathrm{Cm}^{-1}$. Поскольку, согласно ['], этот же максимум оказывается наиболее интенсивным и для 1-метил-, 1-этил- и 1-пропилциклогексенов, то он обусловлен, вероятно, присутствием олефиновой связи и длинной боковой цепи. Для 3-аллилциклогексена в группе, состоящей из трех максимумов, два первых (687 и $\left.699 \mathrm{~cm}^{-1}\right)$ настолько сближаются, что максимум (699) наблюдается в виде плеча на максимуме $687 \mathrm{~cm}^{-1}$. Для спектра же 3-циклогексилциклогексена характерно раздельное присутствие указанных максимумов при длинах волн 670, 696 и $720 \mathrm{~cm}^{-1}$.

3-Фенилциклогексен и 3-бензилциклогексен можно рассматривать как производные бензола, содержащие циклогексеновую группу. Замещенное таким образом ядро бензола имеет типичные максимумы при длинах волн $747-737$ и $701-694 \mathrm{csi}^{-1}\left[{ }^{2}\right]$.

В области $600-810$ c. $^{-1}$ 3-бензилциклогексен-1 и 3-фенилциклогексен-1 имеют максимумы при $670,696,720,743$ и $675,703,725,757 \mathrm{~cm}^{-1}$ соответственно, которые можно нспользовать для их идентификации.

Наиболее характерными для 1-алкилциклогексенов являются максимумы при 721,800 и $920 \mathrm{~cm}^{-1}$. Максимум $800 \mathrm{~cm}^{-1}$ обусловлен неплоскостным деформационным колебанием группы $\mathrm{CH}=$. Поскольку частота $720 \mathrm{~cm}^{-1}$ не наблюдается в спектрах 1-метил-, 1-этил-, 1-пропил-, 1-бутилциклогексенов [ $\left.{ }^{1}\right]$, то можно предположить, что этот максимум обусловлен присутствием в молекуле длинной алкильной цепи. В спектрах 1-алкилциклогексенов названный максимум очень мало выражен у 1-изоамилциклогексена и отсутствует у 1-аллилциклогексена.

Все исследованные олефиновые углеводороды имеют максимумы в области $540-550 \mathrm{~cm}^{-1}$.

Области $1000-400 \mathrm{~cm}^{-1}$, обладая рядом хорошо выраженных максимумов, позволяют лучше всего идентифицировать соединения цикло- 
гексенового рядда. В этой же области с помощью вышеназванных максимумов можно различать изомеры 1- и 3-циклогексеновых соединений.

Спектры циклогексенов с одним заместителем в кольце, как показывают наши исследования, значительно отличаются от спектров циклогексенов с двумя и тремя заместителями.

Авторы благодарят заведующего сектором физики Института кибернетики АН ЭССР Э. Липпмаа за предоставление прибора UR-10 и сотрудника Института химии И. Пыдер за синтез 3-замещенных циклогексенов.

\section{ЛИТЕРАТ УРА}

1. Ю. Эй зен, С. Р анг, В. К а ск, О. Эй зен, Изв. АН ЭССР. Химия. Геология, 16, № 2, 101-107 (1967).

2. Szymanski H. A., Interpreted Infrared Spectra, Vol. I, Plenum Press, New York, 1964.

3. Shabtai I., Pinchas S., Herling J., Greener C., Gil-Av E., J. Inst. Petr., 48, 13-17 (1962).

\section{Ннститут химии \\ Академии наук Эстонской ССР \\ Поступила в редакцию $12 / \mathrm{X} 1966$}

J. EISEN, S. RANG, V. KASK, O. EISEN

\section{TSUKLOOLEFINSETE SUSIVESINIKE SPEKTRAALANALOUSIST INFRAPUNASES PIIRKONNAS. II}

Määrati ja osalt interpreteeriti 1-pentüül-, 1-heksüül-, 1-heptüül-, 1-oktüül-, 1-nonüül-, 1-fenüül-, 1-bensüül-, 1-allüül-, 1-tsükloheksüül-, 3-pentüül-, 3-heksüül-, 3-heptüül-, 3-oktüül-, 3-nonüül-, 3-fenüül-, 3-bensüül-, 3-allüül-, 3-tsükloheksüültsüklohekseen-1 infrapunased spektrid piirkonnas $3100-400 \mathrm{~cm}^{-1}$.

\section{J. EISEN, S. RANG, V. KASK, O. EISEN}

\section{BEITRAG ZUR ULTRAROTSPEKTROSKOPIE ZYKLOOLEFINISCHER KOHLENWASSERSTOFFE. II}

Es wurden synthesiert: 1-Penthyl-, 1-Hexyl-, 1-Heptyl-, 1-Octyl-, 1-Nonyl-, 1-Phenyl-, 1-Benzyl-, 1-Allyl-, 1-Zyklohexyl-, 3-Penthyl-, 3-Hexyl-, 3-Heptyl-, 3-Octyl-, 3-Nonyl-, 3-Phenyl-, 3-Benzyl-, 3-Allyl-, 3-Zyklohexyl-zyklohexen-1.

Die Spektren der genannten Kohlenwasserstoffe wurden ausgewertet und ihre chemische Konstitutionsaufklärung wurde teilweise durchgeführt. 